\title{
Validation of a quantitative FFQ for a study of diet and risk of colorectal adenoma among Japanese Brazilians
}

\author{
Mohammadreza Pakseresht ${ }^{1}$, Nelson Tomio Miyajima ${ }^{2}$, Andrew Shelton ${ }^{3}$, \\ Motoki Iwasaki ${ }^{4}$, Shoichiro Tsugane ${ }^{4}$, Loic Le Marchand ${ }^{5}$ and Sangita Sharma ${ }^{1, *}$ \\ 'Department of Medicine, 5-10 University Terrace, University of Alberta, Edmonton, Alberta, Canada, \\ T6G 2T4: ${ }^{2}$ Sociedade Beneficente de Cotia Hospital, São Paulo, Brazil: ${ }^{3}$ Nutrition Research Institute, University \\ of North Carolina at Chapel Hill, Kannapolis, NC, USA: ${ }^{4}$ Epidemiology and Prevention Division, Research \\ Center for Cancer Prevention and Screening, National Cancer Center, Tokyo, Japan: ${ }^{5}$ Epidemiology \\ Programme, University of Hawaii Cancer Center, Honolulu, HI, USA
}

Submitted 27 July 2011: Final revision received 15 February 2012: Accepted 17 June 2012: First published online 14 August 2012

\begin{abstract}
Objective: To assess the validity of a 161-item quantitative FFQ (QFFQ) that was developed to evaluate dietary risk factors for a colorectal adenoma case-control study.

Design: A cross-sectional validation study of the QFFQ against $4 \mathrm{~d}$ food diary using Pearson correlation coefficients, cross-classification, weighted $\kappa$ statistics and Bland-Altman plotting.

Setting: Two hospitals in São Paulo, Brazil.

Subjects: Ninety-seven healthy Japanese-Brazilian adults (40-75 years) were recruited. One participant was excluded from the analysis due to unusual energy intake report.

Results: Mean daily nutrient intakes from the QFFQ were higher than from the food diary. The mean Pearson correlation coefficient for nutrient intakes between the QFFQ and the average of the $4 \mathrm{~d}$ food diary was 0.43 , and increased to 0.45 after correcting correlations for attenuation due to residual day-to-day variation in the food diary measurements. Adjustment for total energy and further adjustment for age and gender decreased the correlation; however, $77 \%$ of observations remained in the same or adjacent quartiles with a mean weighted $\kappa$ of $0 \cdot 22$. Bland-Altman plots on $\log _{e}$-transformed data showed no linear trend between the differences and means for energy, fat, protein, total folate and vitamin C. Compared with the food diary, the QFFQ showed consistently reasonable performance for dietary fibre, total folate, retinol, riboflavin and vitamin C. Conclusions: This investigation supports the relative validity of the QFFQ as a method for assessing long-term dietary intake. The instrument will be a useful tool in the analysis of diet-adenoma associations in the case-control study.
\end{abstract}

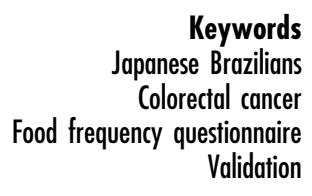

The largest ethnic Japanese population living outside Japan resides in São Paulo, Brazil, with 350000 Japanese living in the city of São Paulo and an additional 900000 in the state of São Paulo(1). Japanese may be more prone to developing colorectal cancer (CRC) when exposed to a Western lifestyle, including a diet high in fat and red meat ${ }^{(2)}$, possibly due to genetic susceptibility ${ }^{(3)}$. Japanese immigrants to Brazil appear to rapidly adopt a diet that is relatively high in fat, obtaining $32 \%$ of energy from fat compared with $25 \%$ for Japanese living in Japan $^{(4)}$. Consumption of Brazilian churrasco, or barbecued meat, may further increase the risk of CRC due to its high concentration of chemical carcinogens such as heterocyclic amines and polycyclic aromatic hydrocarbons ${ }^{(5-8)}$. Conversely, Japanese Brazilians also consume large quantities of fruits, vegetables and legumes that may be protective against $\mathrm{CRC}^{(9)}$.

As the fourth most common malignancy in Brazil, CRC incidence remains proportionally low compared with that in many developed countries, including Japan. However, current data show that the trend of CRC mortality in Japanese Brazilians resembles the higher rates of Japan more than those of the Brazilian population ${ }^{(10)}$. An assessment of the effect of diet and diet-gene interaction on adenoma, a precursor lesion for CRC, in this population may shed some light on the reasons for this risk pattern.

The FFQ is a popular and effective dietary assessment instrument for studies on diet-disease associations, but it must be developed and validated specifically for the target population ${ }^{(11)}$. While FFQ have been previously 
validated for use with Japanese-Brazilian populations ${ }^{(12,13)}$, those instruments are not well suited for investigating the relationship between diet and adenoma or CRC risk. The validations were performed only with female populations, while CRC incidence is higher among males. To address these issues a quantitative FFQ (QFFQ) was developed ${ }^{(14)}$ for the assessment of dietary intake in a case-control study of colorectal adenoma among the Japanese-Brazilian population. The purpose of the present study was to assess the validity of this QFFQ.

\section{Experimental methods}

\section{Participants}

A total of ninety-seven individuals were randomly selected among the controls of a case-control study of adenoma being conducted among patients undergoing colonoscopy in two hospitals in São Paulo, Brazil, between August 2008 and November 2009. Inclusion criteria were 40-75 years of age, at least three grandparents of pure Japanese ancestry and São Paulo residency for at least 6 months prior to recruitment. Exclusion criteria were a colonoscopy positive for inflammatory bowel disease, hyperplastic polyp, colorectal adenoma or colorectal cancer, or a history of such diseases.

\section{Dietary assessment}

Development of the QFFQ has been described elsewhere $^{(14)}$. Briefly, sixty Japanese Brazilians aged 40-75 years with no history of cancer were recruited from a São Paulo clinic during May and June 2005; respondents completed detailed $24 \mathrm{~h}$ diet recalls administered by a trained, multilingual dietitian in the clinic waiting room. All food and drink items reported by more than one respondent were included in the QFFQ, although items with very low energy and nutrient density (i.e. condiments and spices) were excluded. Items of comparable nutrient profile (i.e. different varieties of yoghurt) were grouped as a single item, resulting in a final QFFQ containing 161 foods and drinks to assess usual food and drink intake over the past 12 months. Assessment of consumption frequency used eight categories (ranging from 'never or hardly ever' to 'two or more times per day'), while portion size was determined by asking respondents to evaluate their typical serving compared with culturally appropriate utensils and food models of known weight.

The validity of the QFFQ was assessed against $4 \mathrm{~d}$ food diaries. The diaries were recorded after inviting participants to the clinic and collecting informed consent. Respondents were instructed to keep a written log of all food and drink intake throughout four consecutive $24 \mathrm{~h}$ periods, including at least one weekend day. When the diaries were returned, the dietitian went through any anomalies with the participant. The dietitian also called participants each day to answer any queries they had regarding the diary. The QFFQ was administered by a dietitian in the clinic. QFFQ administration took place within a maximum of 2 weeks after return of the diaries, ensuring overlap between the covered periods. The $4 \mathrm{~d}$ food diaries were given before the QFFQ to help the participants become familiar with portion sizes and the recording process.

The study was approved by the University of Hawaii, Committee on Human Studies, as well as the Brazilian Ministries of Health, Science and Technology, and of Foreign Affairs, and the Brazilian National Ethics Commission.

\section{Analysis}

Collected information was double-checked for missing data and frequently forgotten items. To perform statistical analyses, the statistical software package STATA MP version $10 \cdot 1$ was used.

Daily intake of each food item was determined for each participant. The frequency categories were converted to number of times per day. Daily grams were computed for each food item as the daily frequency multiplied by the portion size converted to grams. For each seasonal food, the frequencies were adjusted by multiplying the proportion of months per year for which the food item was available.

Using the US Department of Agriculture's food composition table and local recipes, a food composition database was specifically prepared to accommodate the dietary characteristics among the study population to calculate daily nutrient intakes from the QFFQ. Each of the 161 food items had a record in the food composition database that provided the amount of nutrient per $100 \mathrm{~g}$ of food. For food items that represented food groups, such as 'French bread, homemade bread and Italian bread', the records are averages of the food composition of the relevant foods, weighted by the frequency of consumption based on our previously collected data ${ }^{(14)}$. The data extracted from three data sets, including the food composition database, QFFQ (frequency and amount of intake) and food item portion weights, were analysed by the Food Frequency Questionnaire Analysis Program in STATA (FFQAPIS) - programmed by the first author - to compute total daily nutrient intake.

All food diary data were coded, entered and analysed using NutriBase Clinical Nutrition Manager version $5 \cdot 18$. NutriBase calculated the nutrient intake for each individual diary per person based on the US Department of Agriculture's food composition table. An estimate of individual $j$ 's daily intake of nutrient $k\left(Y_{j k}\right)$, as given by $24 \mathrm{~h}$ recalls in $n$ weekdays and $m$ weekend days, was computed using the following formula:

$$
Y_{j k}=\left[\left(\frac{5}{n} \sum_{d=0}^{n} Y_{j k d}\right)+\left(\frac{2}{m} \sum_{d=0}^{m} Y_{j k d}\right)\right] \div 7
$$




\section{Statistical metbods}

The ultimate objective of the study was to measure the validity of the QFFQ to be used in a case-control study examining dietary intake and risk of colorectal adenoma among Japanese Brazilians in São Paulo. Accordingly, all statistical analyses were carried out on total daily intakes of energy and nineteen nutrients of interest. Mean and standard deviation for nutrients were computed for both the QFFQ and $4 \mathrm{~d}$ food diaries. All nutrients were $\log _{\mathrm{e}}$-transformed before inclusion in the analyses because they tended to be positively skewed. Pearson's productmoment correlation $(r)$ was used to measure the strength of the relationship between nutrient intakes estimated by the QFFQ and the reference tool. Cross-classification was used to evaluate the relative agreement between the two tools. The quartiles were created using the instrumentspecific distribution. The percentage in the same quartile was calculated as a measure of agreement. The weighted $\kappa$ was computed to provide a chance-corrected measure of cross-classification ${ }^{(15)}$. All $P$ values were two sided and significant at $<0 \cdot 05$.

Within-person variance (i.e. day-to-day variation in diet) measured in the diaries can attenuate correlations between the QFFQ and $4 \mathrm{~d}$ diary ${ }^{(16)}$. To adjust for this, the crude Pearson correlations were de-attenuated using the following formula: $\left\{1+\left[\left(\sigma_{\mathrm{W}}^{2} / \sigma_{\mathrm{B}}^{2}\right) / m\right]\right\}^{0.5}$, where $m$ is the average number of days covered by the diary, and the within-person $\left(\sigma_{\mathrm{W}}^{2}\right)$ and between-person $\left(\sigma_{\mathrm{B}}^{2}\right)$ variances were computed from the $4 \mathrm{~d}$ diary by variance component techniques ${ }^{(17)}$. Most nutrient intakes were positively correlated for energy intake, thus the regression model method ${ }^{(18)}$ was used to calculate energy-adjusted nutrients to remove variation due to energy.

Bland-Altman plots were used to observe the agreement between the QFFQ and dietary recall at the individual level $^{(19)}$. Because of skewness in the dietary data, $\log _{\mathrm{e}}$ transformation was carried out on dietary data before analysis. The measurement error is shown by plotting the individual difference between the pair of measurements $v$. the average of the paired measurements. To be able to interpret findings on plots, antilogs of mean, upper and lower limits of agreement were calculated. These indices, respectively, show the ratio QFFQ: $4 \mathrm{~d}$ diary for nutrient data on average plus or minus twice the standard deviation of the difference ${ }^{(19)}$. A linear regression line of differences was fitted to examine the degree of concordance between the QFFQ and $4 \mathrm{~d}$ diary, where a complete concordance is met with a slope $(\beta)$ of zero.

\section{Results}

Ninety-seven Japanese-Brazilian adults completed the $4 \mathrm{~d}$ diary and were interviewed for the QFFQ. Only one person had an energy intake of $<4184 \mathrm{~kJ}(3987 \mathrm{~kJ})$; the diary was discussed between the participant and the dietitian and the information was verified. After excluding one (1\%) participant with total daily energy report of more than $21000 \mathrm{~kJ}$, fifty-eight $(60 \%)$ women and thirty-eight (40\%) men, with mean age of 58 (SD 10) years and 61 (SD 10) years, respectively, were included in the analysis. The $4 \mathrm{~d}$ diaries were collected over $384 \mathrm{~d}$ covering both weekdays and weekends.

The mean intakes of energy, macronutrients and some micronutrients of interest are presented in Table 1 for comparison between the two instruments. Mean intakes of all of nutrients included in Table 1 were greater for the QFFQ than the average of the $4 \mathrm{~d}$ diary.

Comparing QFFQ and $4 \mathrm{~d}$ diaries, the crude Pearson correlation coefficients ranged from $0 \cdot 23$ for $\alpha$-carotene to $0 \cdot 70$ for ethanol with a total average of $0 \cdot 40$. After correction for within-person variance, the correlation coefficient for macronutrients ranged from $0.39(P<0.01)$ for total fat to $0.76(P<0 \cdot 01)$ for ethanol. Among micronutrients under assessment, the weakest and strongest de-attenuated correlations between the two dietary tools were observed for $\alpha$-carotene $(r=0 \cdot 25, P<0 \cdot 05)$ and total folate $(r=0.52$, $P<0 \cdot 01)$, respectively. In the present study, adjustment for energy decreased correlation coefficients between the QFFQ and the $4 \mathrm{~d}$ diary for all nutrients of interest, except $\alpha$-carotene.

Further adjustment for variation in intake based on age and sex among participants led to more attenuation in overall correlation $(r=0 \cdot 24$ for energy-adjusted intake values to $r=0 \cdot 22$ for age-, sex- and energy-adjusted intake values).

Cross-classification analysis by quartiles revealed complete agreement between the QFFQ and $4 \mathrm{~d}$ diary for an average of $41 \%$ of observations for energy, dietary fibre and macronutrients and $36 \%$ of observations for micronutrients (Table 2). Seventy-eight per cent of observations for energy, dietary fibre and macronutrients and $78 \%$ of observations for micronutrients were placed in the same or adjacent quartiles with an average weighted $\kappa$ of $0 \cdot 30$ and $0 \cdot 26$, respectively. Extreme misclassification ranged between 2\% (retinol) and 10\% ( $\gamma$-tocopherol). The sum of proportions of same, adjacent and opposite quartiles in each row of Table 2 is not equal to $100 \%$ because the proportions of moderate misclassifications are not included in the table. On average, a slightly higher proportion of observations related to macronutrient consumption was placed in the same or adjacent quartiles before adjustment (76\%) compared with after adjustment for energy (74\%). This attenuation in agreement was more obvious for micronutrients where the proportion decreased from $78 \%$ before adjustment to $74 \%$ after adjustment for energy. In addition, the average weighted $\kappa$ for nutrient variables decreased from 0.27 to 0.23 after adjustment.

Considering linear trend $P$ values in the Bland-Altman plots on $\log _{\mathrm{e}}$-transformed data there were no significant linear trends between the differences and means for 
Table 1 Mean daily nutrient intakes estimated by the quantitative FFQ (QFFQ) and the $4 \mathrm{~d}$ diary, and Pearson correlation coefficients ( $r$ ) between the crude and adjusted estimations from two questionnaires, among healthy Japanese-Brazilian adults aged $40-75$ years ( $n$ 96), São Paulo, Brazil, August 2008-November 2009

\begin{tabular}{|c|c|c|c|c|c|c|c|c|}
\hline \multirow[b]{2}{*}{ Nutrient } & \multicolumn{2}{|c|}{ QFFQ } & \multicolumn{2}{|c|}{$4 \mathrm{~d}$ diary } & \multicolumn{4}{|c|}{ Pearson correlation coefficient $(r)$} \\
\hline & Mean & SD & Mean & SD & Crudet & De-attenuatedt & $\begin{array}{l}\text { De-attenuated and } \\
\text { energy-adjusted }\end{array}$ & $\begin{array}{c}\text { De-attenuated and } \\
\text { age-, sex- and } \\
\text { energy-adjusted }\end{array}$ \\
\hline Energy (kJ) & 10800 & 3400 & 7100 & 2100 & $0 \cdot 48^{\star \star}$ & $0 \cdot 49^{\star \star}$ & - & - \\
\hline Total fat $(\mathrm{g})$ & 81 & 26 & 49 & 18 & $0 \cdot 38^{\star *}$ & $0 \cdot 39^{\star *}$ & $0 \cdot 23^{*}$ & $0 \cdot 17$ \\
\hline Protein $(\mathrm{g})$ & 92 & 31 & 72 & 25 & $0 \cdot 44^{\star \star}$ & $0.45^{\star \star}$ & 0.04 & 0.03 \\
\hline Ethanol (g) & $3 \cdot 1$ & $9 \cdot 0$ & $1 \cdot 4$ & $3 \cdot 9$ & $0 \cdot 70^{\star *}$ & $0 \cdot 76^{\star *}$ & $0 \cdot 29^{\star *}$ & $0 \cdot 30^{\star *}$ \\
\hline Carbohydrate (g) & 384 & 138 & 249 & 73 & $0 \cdot 45^{\star \star}$ & $0 \cdot 46^{\star *}$ & $0 \cdot 25^{\star}$ & $0 \cdot 22^{\star}$ \\
\hline Dietary fibre $(\mathrm{g})$ & 38 & 18 & 20 & $8 \cdot 0$ & $0 \cdot 42^{\star \star}$ & $0 \cdot 43^{\star \star}$ & $0 \cdot 39^{\star \star}$ & $0 \cdot 34^{\star \star}$ \\
\hline Total folate $(\mu \mathrm{g})$ & 756 & 282 & 536 & 196 & $0.51^{\star \star}$ & $0.52^{\star *}$ & $0 \cdot 42^{\star \star}$ & $0 \cdot 39^{\star *}$ \\
\hline Retinol $(\mu \mathrm{g})$ & 213 & 97 & 193 & 155 & $0 \cdot 48^{* *}$ & $0.50^{\star \star}$ & $0 \cdot 36^{\star *}$ & $0 \cdot 34^{\star *}$ \\
\hline Riboflavin (mg) & $2 \cdot 0$ & 0.7 & $1 \cdot 5$ & 0.5 & $0 \cdot 45^{\star \star}$ & $0 \cdot 46^{\star \star}$ & $0 \cdot 43^{\star \star}$ & $0 \cdot 39^{\star *}$ \\
\hline Vitamin $B_{6}(\mathrm{mg})$ & $2 \cdot 9$ & $1 \cdot 1$ & $1 \cdot 8$ & $0 \cdot 6$ & $0 \cdot 36^{\star \star}$ & $0 \cdot 37^{\star *}$ & $0 \cdot 32^{\star *}$ & $0 \cdot 26^{\star}$ \\
\hline Vitamin $B_{12}(\mu \mathrm{g})$ & $4 \cdot 8$ & $2 \cdot 4$ & $3 \cdot 8$ & $2 \cdot 9$ & $0 \cdot 25^{\star}$ & $0 \cdot 26^{\star}$ & 0.04 & 0.06 \\
\hline Vitamin C (mg) & 365 & 201 & 165 & 105 & $0 \cdot 49^{* *}$ & $0.51^{\star *}$ & $0 \cdot 36^{\star *}$ & $0 \cdot 35^{\star *}$ \\
\hline Vitamin D ( $\mu \mathrm{g})$ & $2 \cdot 4$ & $1 \cdot 0$ & $1 \cdot 7$ & 1.5 & $0 \cdot 34^{\star *}$ & $0 \cdot 35^{\star *}$ & $0 \cdot 18$ & $0 \cdot 20$ \\
\hline$\alpha$-Carotene $(\mu \mathrm{g})$ & 1057 & 690 & 708 & 570 & $0 \cdot 23^{\star}$ & $0 \cdot 25^{\star}$ & $0 \cdot 27^{\star}$ & $0 \cdot 26^{\star}$ \\
\hline$\beta$-Carotene $(\mu \mathrm{g})$ & 6140 & 3029 & 4082 & 2624 & $0 \cdot 26^{*}$ & $0 \cdot 28^{*}$ & $0 \cdot 17$ & $0 \cdot 13$ \\
\hline$\alpha$-Tocopherol (mg) & 11 & $4 \cdot 4$ & $4 \cdot 6$ & 1.9 & $0 \cdot 42^{\star \star}$ & $0 \cdot 44^{\star \star}$ & $0 \cdot 37^{\star \star}$ & $0 \cdot 30^{\star \star}$ \\
\hline$\gamma$-Tocopherol (mg) & $1 \cdot 4$ & 0.6 & $1 \cdot 1$ & $1 \cdot 2$ & $0 \cdot 28^{\star \star}$ & $0 \cdot 31^{\star *}$ & $0 \cdot 11$ & $0 \cdot 11$ \\
\hline Methionine $(\mathrm{g})$ & $1 \cdot 6$ & $0 \cdot 6$ & 1.5 & $0 \cdot 6$ & $0 \cdot 41^{\star \star}$ & $0 \cdot 43^{\star \star}$ & 0.02 & 0.02 \\
\hline Lutein $(\mu \mathrm{g})$ & 5848 & 3388 & 3202 & 3441 & $0 \cdot 29^{\star \star}$ & $0 \cdot 32^{\star *}$ & $0 \cdot 10$ & 0.07 \\
\hline $\mathrm{Ca}(\mathrm{mg})$ & 1089 & 420 & 686 & 337 & $0 \cdot 28^{\star \star}$ & $0 \cdot 30^{\star *}$ & $0 \cdot 19$ & $0 \cdot 15$ \\
\hline
\end{tabular}

${ }^{\star} P<0.05,{ }^{* *} P<0.01$.

tCorrelation coefficients are based on $\log _{\mathrm{e}}$-transformed values of nutrient intake.

Table 2 Cross-classification of nutrient distribution quartiles from the quantitative FFQ (QFFQ) and the $4 \mathrm{~d}$ diary among healthy JapaneseBrazilian adults aged 40-75 years ( $n$ 96), São Paulo, Brazil, August 2008-November 2009

\begin{tabular}{|c|c|c|c|c|c|c|c|c|}
\hline \multirow[b]{2}{*}{ Nutrient } & \multicolumn{3}{|c|}{ Crude estimation of nutrient intake } & \multirow[b]{2}{*}{$\begin{array}{l}\text { Weighted } \kappa \text { for } \\
\text { crude values }\end{array}$} & \multicolumn{3}{|c|}{ Energy-adjusted nutrient intake } & \multirow[b]{2}{*}{$\begin{array}{l}\text { Weighted } \kappa \text { for } \\
\text { adjusted values }\end{array}$} \\
\hline & $\begin{array}{c}\text { Same } \\
\text { quartile (\%) }\end{array}$ & $\begin{array}{c}\text { Adjacent } \\
\text { quartile (\%) }\end{array}$ & $\begin{array}{c}\text { Opposite } \\
\text { quartile (\%) }\end{array}$ & & $\begin{array}{c}\text { Same } \\
\text { quartile (\%) }\end{array}$ & $\begin{array}{c}\text { Adjacent } \\
\text { quartile (\%) }\end{array}$ & $\begin{array}{c}\text { Opposite } \\
\text { quartile (\%) }\end{array}$ & \\
\hline Energy & 46 & 34 & 4 & $0 \cdot 37$ & - & - & - & - \\
\hline Total fat & 38 & 38 & 6 & $0 \cdot 25$ & 35 & 38 & 8 & $0 \cdot 19^{\star *}$ \\
\hline Protein & 41 & 34 & 4 & $0 \cdot 29$ & 33 & 36 & 13 & $0 \cdot 10$ \\
\hline Ethanol & 35 & 39 & 3 & $0 \cdot 15$ & 43 & 39 & 5 & $0 \cdot 35^{\star *}$ \\
\hline Carbohydrate & 46 & 32 & 6 & $0 \cdot 34$ & 31 & 39 & 12 & $0 \cdot 10$ \\
\hline Dietary fibre & 38 & 40 & 4 & 0.29 & 38 & 43 & 5 & $0 \cdot 30^{\star *}$ \\
\hline Total folate & 40 & 39 & 3 & $0 \cdot 32$ & 34 & 46 & 4 & $0 \cdot 27^{\star \star}$ \\
\hline Retinol & 38 & 44 & 2 & $0 \cdot 34$ & 34 & 42 & 4 & $0 \cdot 24^{\star \star}$ \\
\hline Riboflavin & 39 & 41 & 3 & 0.32 & 37 & 39 & 5 & $0 \cdot 25^{\star *}$ \\
\hline Vitamin $\mathrm{B}_{6}$ & 44 & 39 & 5 & 0.37 & 36 & 42 & 6 & $0 \cdot 25^{\star *}$ \\
\hline Vitamin $B_{12}$ & 26 & 47 & 7 & $0 \cdot 14$ & 27 & 35 & 9 & 0.04 \\
\hline Vitamin C & 36 & 49 & 5 & 0.32 & 32 & 48 & 6 & $0 \cdot 24^{\star *}$ \\
\hline Vitamin D & 37 & 44 & 4 & $0 \cdot 30$ & 30 & 41 & 7 & $0 \cdot 14^{*}$ \\
\hline$\alpha$-Carotene & 30 & 45 & 5 & $0 \cdot 20$ & 34 & 43 & 5 & $0 \cdot 24^{\star *}$ \\
\hline$\beta$-Carotene & 35 & 37 & 7 & $0 \cdot 19$ & 36 & 36 & 10 & $0 \cdot 17^{\star}$ \\
\hline$\alpha$-Tocopherol & 36 & 44 & 4 & $0 \cdot 29$ & 26 & 44 & 4 & $0 \cdot 14^{*}$ \\
\hline$\gamma$-Tocopherol & 34 & 36 & 10 & $0 \cdot 14$ & 32 & 38 & 15 & 0.09 \\
\hline Methionine & 39 & 36 & 6 & $0 \cdot 25$ & 23 & 41 & 12 & 0.01 \\
\hline Lutein & 33 & 40 & 8 & $0 \cdot 17$ & 32 & 44 & 8 & $0 \cdot 19^{* *}$ \\
\hline $\mathrm{Ca}$ & 34 & 43 & 7 & $0 \cdot 22$ & 41 & 35 & 5 & $0 \cdot 29^{\star *}$ \\
\hline
\end{tabular}

Weighted $\kappa$ was calculated for each nutrient from the observed and expected proportions on a $4 \times 4$ table of frequency.

${ }^{\star} P<0.05,{ }^{* *} P<0.01$.

energy, fat, protein, total folate and vitamin C (Fig. 1). Similarly, the slope of fitted regression lines indicates equal variability between the QFFQ and $4 \mathrm{~d}$ diary for measurement of those dietary data. However, the QFFQ and $4 \mathrm{~d}$ diary were not equally variable for measurement of carbohydrate, Ca and vitamin D intakes. Antilog of mean difference values showed that, on average, compared with the $4 \mathrm{~d}$ diary, the QFFQ estimated $45 \%$ higher energy, $65 \%$ higher fat, $23 \%$ higher protein, $42 \%$ higher total folate and $123 \%$ higher vitamin C. 

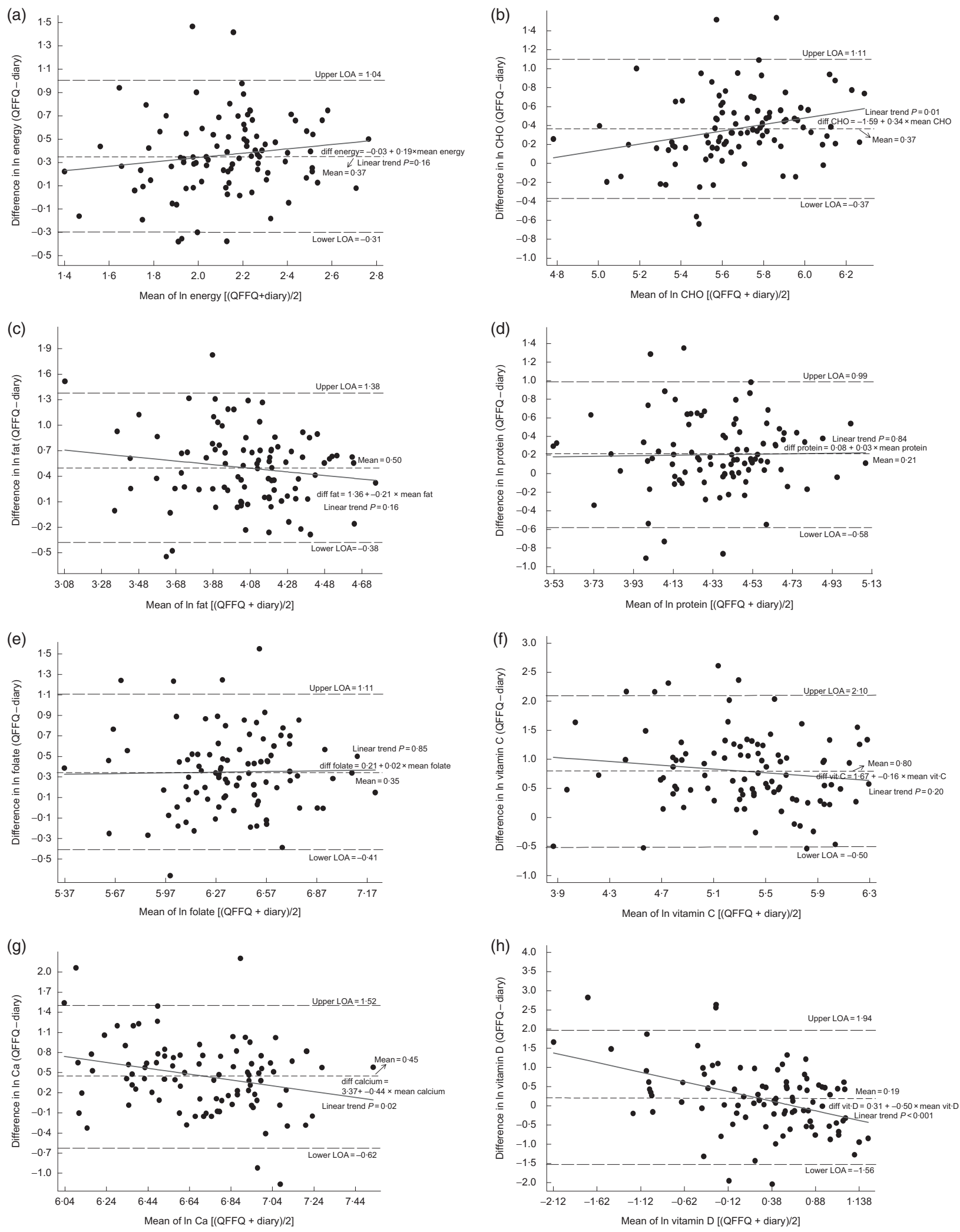

Fig. 1 Bland-Altman plots assessing agreement between the quantitative FFQ (QFFQ) and the $4 \mathrm{~d}$ diary for dietary intake of (a) energy, (b) carbohydrate (CHO), (c) total fat, (d) protein, (e) total folate, (f) vitamin $\mathrm{C}$, (g) vitamin D and (h) calcium among healthy Japanese-Brazilian adults aged 40-75 years ( $n$ 96), São Paulo, Brazil, August 2008-November 2009. Plots were created on $\log _{\mathrm{e}}$-transformed values of energy and nutrients (LOA, limit of agreement) 
Table 3 Pearson correlation coefficient ( $r$ ) between nutrient intakes estimated by the quantitative FFQ (QFFQ) and the $4 \mathrm{~d}$ diary, according to sex, among healthy Japanese-Brazilian adults aged 40-75 years ( $n$ 96), São Paulo, Brazil, August 2008-November 2009

\begin{tabular}{|c|c|c|c|c|c|c|}
\hline \multirow[b]{2}{*}{ Nutrient } & \multicolumn{3}{|c|}{ Men ( $n$ 38) } & \multicolumn{3}{|c|}{ Women ( $n$ 58) } \\
\hline & Crudet & $\begin{array}{l}\text { De-attenuated and } \\
\text { energy-adjusted }\end{array}$ & $\begin{array}{l}\text { De-attenuated and age- } \\
\text { and energy-adjusted }\end{array}$ & Crudet & $\begin{array}{l}\text { De-attenuated and } \\
\text { energy-adjusted }\end{array}$ & $\begin{array}{l}\text { De-attenuated and age- } \\
\text { and energy-adjusted }\end{array}$ \\
\hline Energy & $0.35^{*}$ & - & - & $0 \cdot 38^{\star *}$ & - & - \\
\hline Total fat & $0 \cdot 24$ & $0 \cdot 11$ & $0 \cdot 11$ & $0 \cdot 42^{\star \star}$ & $0 \cdot 33^{*}$ & 0.23 \\
\hline Protein & $0 \cdot 37^{*}$ & NC & $\mathrm{NC}$ & $0 \cdot 28^{*}$ & 0.02 & 0.03 \\
\hline Ethanol & $0 \cdot 68^{\star \star}$ & $0 \cdot 25$ & 0.25 & $0 \cdot 64^{\star \star}$ & $0 \cdot 66^{\star \star}$ & $0 \cdot 66^{\star \star}$ \\
\hline Carbohydrate & $0 \cdot 33^{\star}$ & $0 \cdot 21$ & $0 \cdot 21$ & $0 \cdot 38^{\star \star}$ & $0 \cdot 32^{*}$ & 0.25 \\
\hline Dietary fibre & $0 \cdot 36^{*}$ & $0 \cdot 45^{\star *}$ & $0 \cdot 45^{\star *}$ & $0 \cdot 44^{* *}$ & $0 \cdot 36^{* *}$ & $0 \cdot 24$ \\
\hline Total folate & $0 \cdot 37^{\star}$ & $0 \cdot 37^{\star}$ & $0 \cdot 39^{*}$ & $0 \cdot 37^{\star \star}$ & $0 \cdot 41^{\star *}$ & $0 \cdot 37^{\star \star}$ \\
\hline Retinol & $0 \cdot 45^{\star \star}$ & $0 \cdot 26$ & $0 \cdot 24$ & $0 \cdot 49^{\star *}$ & $0 \cdot 44^{\star \star}$ & $0 \cdot 46^{\star *}$ \\
\hline Riboflavin & $0 \cdot 41^{*}$ & $0 \cdot 53^{\star \star}$ & $0 \cdot 51^{\star \star}$ & $0 \cdot 41^{\star \star}$ & $0 \cdot 31^{\star}$ & $0 \cdot 31^{*}$ \\
\hline Vitamin $B_{6}$ & 0.26 & $0 \cdot 33$ & $0 \cdot 29$ & $0 \cdot 30^{\star}$ & $0 \cdot 32^{*}$ & $0 \cdot 25$ \\
\hline Vitamin $B_{12}$ & $0 \cdot 30$ & $0 \cdot 15$ & $0 \cdot 15$ & $0 \cdot 16$ & NC & NC \\
\hline Vitamin C & $0 \cdot 33^{*}$ & $0 \cdot 30$ & $0 \cdot 32$ & $0.57^{\star *}$ & $0.53^{\star *}$ & $0 \cdot 46^{\star \star}$ \\
\hline Vitamin D & $0 \cdot 16$ & $0 \cdot 13$ & $0 \cdot 13$ & $0 \cdot 46^{\star *}$ & $0 \cdot 24$ & $0 \cdot 29^{*}$ \\
\hline$\alpha$-Carotene & $0 \cdot 22$ & $0 \cdot 16$ & $0 \cdot 12$ & $0 \cdot 36^{\star \star}$ & $0 \cdot 37^{*}$ & $0 \cdot 36^{\star}$ \\
\hline$\beta$-Carotene & $0 \cdot 23$ & $0 \cdot 11$ & $0 \cdot 11$ & $0 \cdot 30^{\star}$ & $0 \cdot 20$ & $0 \cdot 16$ \\
\hline$\alpha$-Tocopherol & $0 \cdot 42^{\star *}$ & $0.53^{\star *}$ & $0.53^{\star *}$ & $0 \cdot 43^{\star *}$ & $0 \cdot 21$ & $0 \cdot 21$ \\
\hline$\gamma$-Tocopherol & $0 \cdot 26$ & 0.07 & $0 \cdot 07$ & $0 \cdot 25$ & $0 \cdot 15$ & $0 \cdot 15$ \\
\hline Methionine & $0 \cdot 38^{*}$ & 0.02 & 0.03 & $0 \cdot 19$ & NC & NC \\
\hline Lutein & $0 \cdot 32^{*}$ & NC & NC & $0 \cdot 28^{\star}$ & 0.25 & $0 \cdot 25$ \\
\hline $\mathrm{Ca}$ & $0 \cdot 36^{\star}$ & $0 \cdot 45^{\star \star}$ & $0 \cdot 44^{\star \star}$ & $0 \cdot 22$ & 0.06 & 0.02 \\
\hline
\end{tabular}

NC, no correlation.

${ }^{*} P<0.05,{ }^{* \star} P<0.01$.

tCorrelation coefficients are based on $\log _{\mathrm{e}}$-transformed values of nutrient intake.

A subgroup analysis for gender showed smaller correlation coefficients between the two methods among men compared with women for all nutrients, except vitamin $\mathrm{B}_{12}$, methionine and $\mathrm{Ca}$ (Table 3). The average correlation coefficient adjusted for age and daily energy intake was 0.23 for men and 0.25 for women, but were not statistically different $(P=0 \cdot 42)$.

\section{Discussion}

The validity of an FFQ is the degree to which the instrument measures the diet of the subjects it was designed to study. Typically, nutrient intake estimation by an FFQ is compared with a standard reference method. The comparison can be made by looking at the relative ranking of subjects by the two methods and examining the absolute levels of both methods ${ }^{(20)}$. There are no gold standard dietary assessment tools for measuring dietary intake. However, when choosing a reference tool for a validation study, it is important that the sources of error for the reference tool and FFQ are as independent as possible. The major sources of error in the FFQ are poor recall, interpretation of questions and inference of portion sizes provided in the questionnaire. These errors are unlikely to apply to the food diary and this dietary assessment tool is feasible for implementation ${ }^{(21)}$. Utilizing biomarker measurements as the most accurate reference for FFQ validation was not considered for the present study because of the high cost involved and the limited number of nutrients that could be evaluated.
Comparison of means indicated a tendency for higher estimation of intake by the QFFQ than the $4 \mathrm{~d}$ diary. However, moderate $(r=0 \cdot 30-0 \cdot 50)$ to good $(r>0 \cdot 50)$ correlation was observed between the two dietary assessment tools for $85 \%$ of the nutrients under study. In addition, more than $70 \%$ of the participants were classified into the same or adjacent quartiles for nutrient intakes indicating an overall moderate to good agreement between the QFFQ and reference tool.

In an FFQ validation study against four $24 \mathrm{~h}$ recalls among eighty-eight Brazilians ${ }^{(22)}$, the mean of correlation coefficients for macronutrients and energy, and five nutrients under study (fat, protein, carbohydrate, vitamin $\mathrm{C}$ and $\mathrm{Ca}$ ) were 0.39 and 0.40 , respectively, and were slightly smaller than the corresponding correlation coefficients in the present study $(0.43$ and 0.43 , respectively). Compared with an FFQ validation study among 104 Brazilian workers ${ }^{(23)}$, the present study demonstrated a slightly higher mean de-attenuated correlation coefficient for energy and the five nutrients in common between the two studies $(0 \cdot 42 \quad v \cdot 0 \cdot 44)$.

A positive correlation between total energy intake and consumption of most nutrients ${ }^{(24)}$ causes confounding in epidemiological studies, particularly in diet-disease relationship assessments. Energy adjustment via regression analysis, instead of nutrient density, eliminates this confounding effect ${ }^{(18)}$. In the current study, adjustment for energy led to decreased agreement between the two instruments for all nutrients, except $\alpha$-carotene. This indicated variability was more related to systematic error of under- and overestimation than to energy intake ${ }^{(18)}$. 
In a literature review of twenty-one studies on FFQ development and validation among Japanese populations, Wakai ${ }^{(25)}$ reported that the median of correlation coefficients between dietary records and FFQ ranged from 0.31 to 0.56 for target nutrients. In addition, the median of de-attenuated energy-adjusted correlation coefficients reported in five studies ranged from 0.43 to $0.52^{(25)}$, which are substantially greater than the median of the corresponding index in our study $(0 \cdot 25)$. The lower accuracy of the QFFQ in the present study in comparison with the Japanese FFQ is plausibly due to the complicated dishes used among Japanese Brazilians, which include traditional Japanese and local Brazilian foods. Also, the number of food items in our study (161) was greater than in the twenty Japanese studies included in that literature review (ranging from nine to 150$)^{(25)}$, which might increase the burden on participants and influence their ability to recall intake frequencies and portion sizes.

The correlation coefficient for ethanol before adjustment for energy was substantially larger than for other nutrients in the present study. An explanation for this finding is high between-person variation of alcohol intake among participants such that some individuals do not consume alcohol, while others consume heavily. The higher deattenuated correlation coefficient for ethanol among women compared with men can be justified in this way. Dietary fibre, total folate, retinol, riboflavin, vitamin C and $\alpha$-tocopherol are other nutrients that performed well in terms of their rank correlation coefficients. This finding is very similar to what Roddam et $a l^{(26)}$ reported for a validation study of a semi-quantitative food group questionnaire against a $7 \mathrm{~d}$ food diary.

The validity of the QFFQ was poor for protein, vitamins $\mathrm{B}_{12}$ and $\mathrm{D}, \boldsymbol{\gamma}$-tocopherol and methionine in all Pearson correlation, cross-classification and weighted $\kappa$ assessments. A limited number of food sources for some nutrients (e.g. vitamin D) or low consumption of the food sources makes it difficult to capture information reliably which may partly explain the low validity of the QFFQ for these nutrients.

Unlike correlation analysis, the cross-classification procedure is able to capture differential under- and overreporting ${ }^{(27)}$. In the present study, despite some differences in estimation of nutrients by the QFFQ and food diary, classification agreement between the two methods was good. More than $70 \%$ of participants were classified by both methods into the same or adjacent quartiles for level of intake estimation of all nutrients. Protein, carbohydrate, $\boldsymbol{\gamma}$-tocopherol and methionine were found with highest rates of gross misclassification.

The Bland-Altman analysis assesses the agreement between two dietary assessment methods across the range of intakes ${ }^{(19)}$. This analysis is able to determine any bias between the two methods; that is, whether there is any systematic difference between the two methods and the extent to which the two methods agree. The ratio
QFFQ:4d diary computed based on antilogs of mean differences indicated overestimation of energy and nutrients by the QFFQ, which ranged from 21\% for vitamin D to $123 \%$ for vitamin C (data not shown). Similarly, in another QFFQ validation study against $4 \mathrm{~d}$ diary for African-origin people in Barbados ${ }^{(28)}$, the largest ratio was reported for vitamin C (62\%). This pattern could be due to a large diversity of food sources of vitamin $C$ that was obtained from the QFFQ (e.g. beverages with added vitamin $\mathrm{C}$, different types of fruits and vegetables) compared with what participants actually got from the limited number of foods over $4 \mathrm{~d}$.

It is highly recommended to develop gender-specific analysis for validation studies which include both men and women ${ }^{(21)}$. Women tended to achieve higher correlations for validity of questionnaire responses than men $(r=0.28 v \cdot r=0.26$ in full adjusted model). This may be due to women spending more time than men in the purchasing and cooking of meals, and they may, therefore, be more aware of food portion sizes and frequency of consumption. Sex differences in the validity of reported intake based on the QFFQ may obscure true sex differences in the relationships between diet and disease ${ }^{(29)}$.

The mean of energy-adjusted correlation coefficients among women in the present study was $0 \cdot 28$, which is smaller than the corresponding value of 0.32 found in an FFQ validation study of fifty-five women of both Brazilian and Japanese ancestry ${ }^{(12)}$. However, our FFQ showed better validity for macronutrients than the other study $(r=0 \cdot 22 v \cdot r=0 \cdot 17)$.

Several studies have shown the under-reporting of consumption among individuals with excess weight, especially among women ${ }^{(30,31)}$. Lack of information on participants' weight and height did not allow an extra adjustment of correlations to be performed for BMI. The aim of the study was to measure validity of the FFQ in dietary assessment among participants over the past 12 months. The reference tool measured the current dietary intake status. It was assumed that people who were classified as cases in the main case-control study were highly likely to have different dietary habits at the time of study - as a consequence of the disease or following a medical recommendation - compared with the past 12 months. However, this was not a matter of concern among the control group. Thus, excluding cases from the study decreased the possibility of underestimation of the correlation between the FFQ and the reference tool. The sample size of the study is slightly less than the suggested value (at least 100) for an optimal correlation coefficient analysis ${ }^{(11)}$; however, it is enough for the Bland-Altman plotting and interpretation and is acceptable considering the small age range, and the study covers an adequate number of replicates per individual $(4 \mathrm{~d})$.

It has been suggested that increasingly long and detailed questionnaires are less likely to obtain additional 
accurate data ${ }^{(16)}$. On the other hand, Wakai ${ }^{(25)}$ indicated slightly higher validity for FFQ with ninety-seven or more food items than for those that included fewer than seventy items. A literature review by Cade $e t$ al. ${ }^{(11)}$ reported a median number of seventy-nine food items (ranging from five to 350) for FFQ. Therefore, the 161-item QFFQ used in the present study is an adequate length. Moreover, it has been designed to be culturally appropriate by containing local and traditional food items and utilizing appropriate portion sizes.

The QFFQ overestimated all nutrients under study when mean of intake from the QFFQ was compared with the $4 \mathrm{~d}$ diary. However, when the aim of a validation study is to rank individuals rather than estimate 'true' intake, finding a good correlation between the tool under assessment and the reference measure, developing regression and calculation of predicted intake - as would be used in the case-control study of colorectal adenoma - may in part overcome the problems associated with overestimation of intake ${ }^{(29)}$.

In summary, the QFFQ was found reasonably valid for the assessment of daily consumption of a number of dietary nutrients. Consequently, this may permit future analyses to examine the relationship between diet and risk of colorectal adenoma by allowing individuals to be categorized by either their reported eating habits or their estimated nutrient intakes.

\section{Acknowledgements}

Source of funding: This research was supported in part by grants from the American Institute for Cancer Research (\# 06A102) and the US National Cancer Institute (R03 CA119682; Principal Investigator: L.L.M.) and a Grant-in-Aid for Scientific Research on Priority Areas (17015049; Principal Investigator: S.T.) from the Ministry of Education, Culture, Sports, Science, and Technology of Japan, the Uehara Memorial Foundation and the Foundation for Promotion of Cancer Research in Japan. Conflicts of interest: The authors have no conflicts of interest. Authors' contributions: M.I., L.L.M. and S.T. developed the conception and design of the study. S.S. developed the QFFQ and contributed to the study design, implementation and oversaw data analyses. N.T.M. was responsible for overseeing all data collection in the field sites as well as ensuring all protocols were adhered to. M.P., S.S. and A.S. assisted in the writing of the manuscript. M.P. also contributed to the data analyses and interpretations of results. All authors critically reviewed the manuscript. Acknowledgements: The authors would like to thank Ms Silvia Lika Ishii and Ms Ritsuko for their help with data collection. The authors wish to thank Mrs Claudia Kunieda, Cristiani Nakashima, Rosa A. Michelani, and all the volunteers who helped in the collection of recipes.

\section{References}

1. Wakisaka K (editor) (1998) The Results of a Survey on the Japanese Population in Brazil. São Paulo: Center for Japan-Brazil Studies.

2. Minami Y, Nishino Y, Tsubono Y et al. (2006) Increase of colon and rectal cancer incidence rates in Japan: trends in incidence rates in Miyagi Prefecture, 1959-1997. J Epidemiol 16, 240-248.

3. Le Marchand L (1999) Combined influence of genetic and dietary factors on colorectal cancer incidence in Japanese Americans. J Natl Cancer Inst Monogr 26, 101-105.

4. Freire RD, Cardoso MA, Shinzato AR et al. (2003) Nutritional status of Japanese-Brazilian subjects: comparison across gender and generation. BrJ Nutr 89, 705-713.

5. Sugimura T (1985) Carcinogenicity of mutagenic heterocyclic amines formed during the cooking process. Mutat Res 150, 33-41.

6. International Agency for Research on Cancer (1994) Some Industrial Chemicals. IARC Monographs on the Evaluation of the Carcinogenic Risks to Humans no. 60. Lyon: IARC.

7. Iwasaki M, Sharma S, Hamada G et al. (2010) Heterocyclic amines content of meat and fish cooked by Brazilian methods. J Food Compost Anal 23, 61-69.

8. Jagerstad M \& Skog K (2005) Genotoxicity of heatprocessed foods. Mutat Res 574, 156-172.

9. Cardoso MA, Hamada GS, de Souza JM et al. (1997) Dietary patterns in Japanese migrants to southeastern Brazil and their descendants. J Epidemiol 7, 198-204.

10. Iwasaki M, Mameri CP, Hamada GS et al. (2008) Secular trends in cancer mortality among Japanese immigrants in the state of São Paulo, Brazil, 1979-2001. Eur J Cancer Prev 17, 1-8.

11. Cade J, Thompson R, Burley V et al. (2002) Development, validation and utilisation of food-frequency questionnaires - a review. Public Health Nutr 5, 567-587.

12. Ishihara J, Iwasaki M, Kunieda CM et al. (2009) Food frequency questionnaire is a valid tool in the nutritional assessment of Brazilian women of diverse ethnicity. Asia Pac J Clin Nutr 18, 76-80.

13. Cardoso MA, Kida AA, Tomita LY et al. (2001) Reproducibility and validity of a food frequency questionnaire among women of Japanese ancestry living in Brazil. Nutr Res 21, $725-733$.

14. Sharma S, Iwasaki M, Kunieda C et al. (2009) Development of a quantitative food frequency questionnaire for assessing food, nutrient, and heterocyclic aromatic amines intake in Japanese Brazilians for a colorectal adenoma case-control study. Int J Food Sci Nutr 60, Suppl. 7, 128-139.

15. Fleiss JL (2003) Statistical Methods for Rates and Proportions. Hoboken, NJ: Wiley-Interscience.

16. Willett W (1998) Food frequency methods. In Nutritional Epidemiology, 2nd ed., pp. 74-90 [W Willett editor]. New York: Oxford University Press.

17. Rosner B \& Willett W (1988) Interval estimates for correlation coefficients corrected for within-person variation: implications for study design and hypothesis testing. Am J Epidemiol 127, 377-386.

18. Willett W \& Stampfer M (1998) Implications of total energy intake for epidemiologic analyses. In Nutritional Epidemiology, 2nd ed., pp. 296-298 [W Willett, editor]. New York: Oxford University Press.

19. Bland JM \& Altman DG (1999) Measuring agreement in method comparison studies. Stat Methods Med Res 8 , $135-160$.

20. Willett W \& Lenart E (1998) Reproducibility and validity of food frequency questionnaires. In Nutritional Epidemiology, 2nd ed., pp. 101-141 [W Willett, editor]. New York: Oxford University Press. 
21. Nelson M (2003) The validation of dietary assessment. In Design and Concepts in Nutritional Epidemiology, 2nd ed., pp. 241-268 [BM Margetts and M Nelson, editors]. New York: Oxford University Press.

22. Sichiei R \& Everhart JE (1998) Validity of a Brazilian food frequency questionnaire against dietary recalls and estimated energy intake. Nutr Res 18, 1649-1659.

23. Fornés NS, Stringhini ML \& Elias BM (2003) Reproducibility and validity of a food-frequency questionnaire for use among low-income Brazilian workers. Public Health Nutr 6, 821-827.

24. Jequier E \& Schutz Y (1983) Long-term measurement of energy expenditure in humans using a respiratory chamber. Am J Clin Nutr 38, 989-998.

25. Wakai K (2009) A review of food frequency questionnaires developed and validated in Japan. J Epidemiol 19, 1-11.

26. Roddam AW, Spencer E, Banks E et al. (2005) Reproducibility of a short semi-quantitative food group questionnaire and its performance in estimating nutrient intake compared with a 7-day diet diary in the Million Women Study. Public Health Nutr 8, 201-213.

27. Friis S, Kruger Kjaer S, Stripp C et al. (1997) Reproducibility and relative validity of a self-administered semiquantitative food frequency questionnaire applied to younger women. J Clin Epidemiol 50, 303-311.

28. Pakseresht M, Sharma S, Cao X et al. (2010) Validation of a quantitative FFQ for the Barbados National Cancer study. Public Health Nutr 14, 426-434.

29. O'Donnell MG, Nelson M, Wise PH et al. (1991) A computerized diet questionnaire for use in diet health education. 1. Development and validation. BrJ Nutr 66, 3-15.

30. Black AE, Goldberg GR, Jebb SA et al. (1991) Critical evaluation of energy intake data using fundamental principles of energy physiology: 2. Evaluating the results of published surveys. Eur J Clin Nutr 45, 583-599.

31. Heitmann BL \& Lissner L (1995) Dietary underreporting by obese individuals - is it specific or non-specific? BMJ 311, 986-989. 